\section{Cureus}

\title{
Laparoscopic Adjustable Gastric Band Slippage Presenting as Chest Pain
}

\author{
Laura K. Herndon ${ }^{1}$, Tej G. Stead ${ }^{2}$, Latha Ganti ${ }^{3}$, Travan Jasper $^{4}$, David Lebowitz ${ }^{5}$ \\ 1. Emergency Medicine, University of Central Florida, Orlando, USA 2. Emergency Medicine, Brown \\ University, Providence, USA 3. Emergency Medicine, Envision Physician Services, Orlando, USA 4. \\ Emergency Medicine, Coliseum Medical Centers / Mercer University School of Medicine, Macon, USA 5. \\ Emergency Medicine, University of Central Florida College of Medicine, Orlando, USA
}

$\square$ Corresponding author: Tej G. Stead, tej_stead@brown.edu

Disclosures can be found in Additional Information at the end of the article

\section{Abstract}

With the increasing popularity of bariatric procedures, complications are also more commonly seen. In this case, the authors discuss the case of a laparoscopic adjustable gastric band (lap band) that slipped from its correct position, diagnosed via plain radiographs. The patient was admitted for gastroenterology consultation and subsequently had her lap band fixed.

Categories: Emergency Medicine, Gastroenterology

Keywords: lap band, bariatric

\section{Introduction}

It is well known that obesity has become a worldwide epidemic and a preventable contributor to many comorbid conditions that are among the leading causes of death such as diabetes mellitus, heart disease, and stroke. According to the Centers for Disease Control (CDC), the prevalence of obesity in the adult population was 39.8\% in 2015-2016 [1]. Management options for obesity include lifestyle adjustments, medical management, and bariatric surgical methods. Surgical methods have been shown to have the highest rate of immediate and long-term weight-loss success, as well as improvement in comorbid conditions [2]. A common bariatric procedure is placement of a laparoscopic adjustable gastric banding (shortened to lap band, or LAGB), which controls the amount of food that can be ingested by requiring the patient to eat only small quantities at a time, which eventually results in satiety with lesser intake as the method for weight control. The LAGB method has been shown to be a safe and effective weight loss strategy with an average weight loss of $40 \%$ of initial excess body weight [3].

Received 06/18/2019 Review began 06/22/2019 Review ended 06/25/2019 Published 07/02/2019

\section{(C) Copyright 2019}

Herndon et al. This is an open access article distributed under the terms of the Creative Commons Attribution License CC-BY 3.0., which permits unrestricted use, distribution, and reproduction in any medium, provided the original author and source are credited.

\section{Case Presentation}

A 50-year-old female presented to the emergency department (ED) with a chief complaint of chest pain. Although she had several risk factors for coronary artery disease, she stated she did not think this was cardiac in nature. Rather, she described the pain as cramping and burning in her chest. It had been going on for two weeks but increasing in intensity. She reported that the spasms worsened after ingesting liquids or solids. Her past medical history included thyroid cancer and gastroesophageal reflux disease (GERD). Surgical history included thyroidectomy and lap band placement several years prior.

She had an appointment for esophagogastroduodenoscopy (EGD) with her gastroenterologist in five days, but her symptoms became so severe so she came to the ED. She was on daily esomeprazole, which normally helped with her reflux but did not anymore. She reported 


\section{Cureus}

globus, nausea, heartburn, and productive bilious nocturnal coughing but denied odynophagia, palpitations, shortness of breath, fever, chills, vomiting, abdominal pain, diarrhea, constipation, blood in stools, dysuria, or hematuria.

Laboratory analysis was unremarkable. Her vital signs were pulse 69, blood pressure 123/83 $\mathrm{mmHg}$, temperature $36.5^{\circ} \mathrm{C}$, respirations $17 / \mathrm{min}$, and pulse oximetry $96 \%$. An abdominal radiograph revealed that the lap band was in nearly horizontal in position, suggesting slippage had occurred (Figure 1). The patient was admitted to the hospital for gastroenterology consultation and eventually got her lap band fixed.

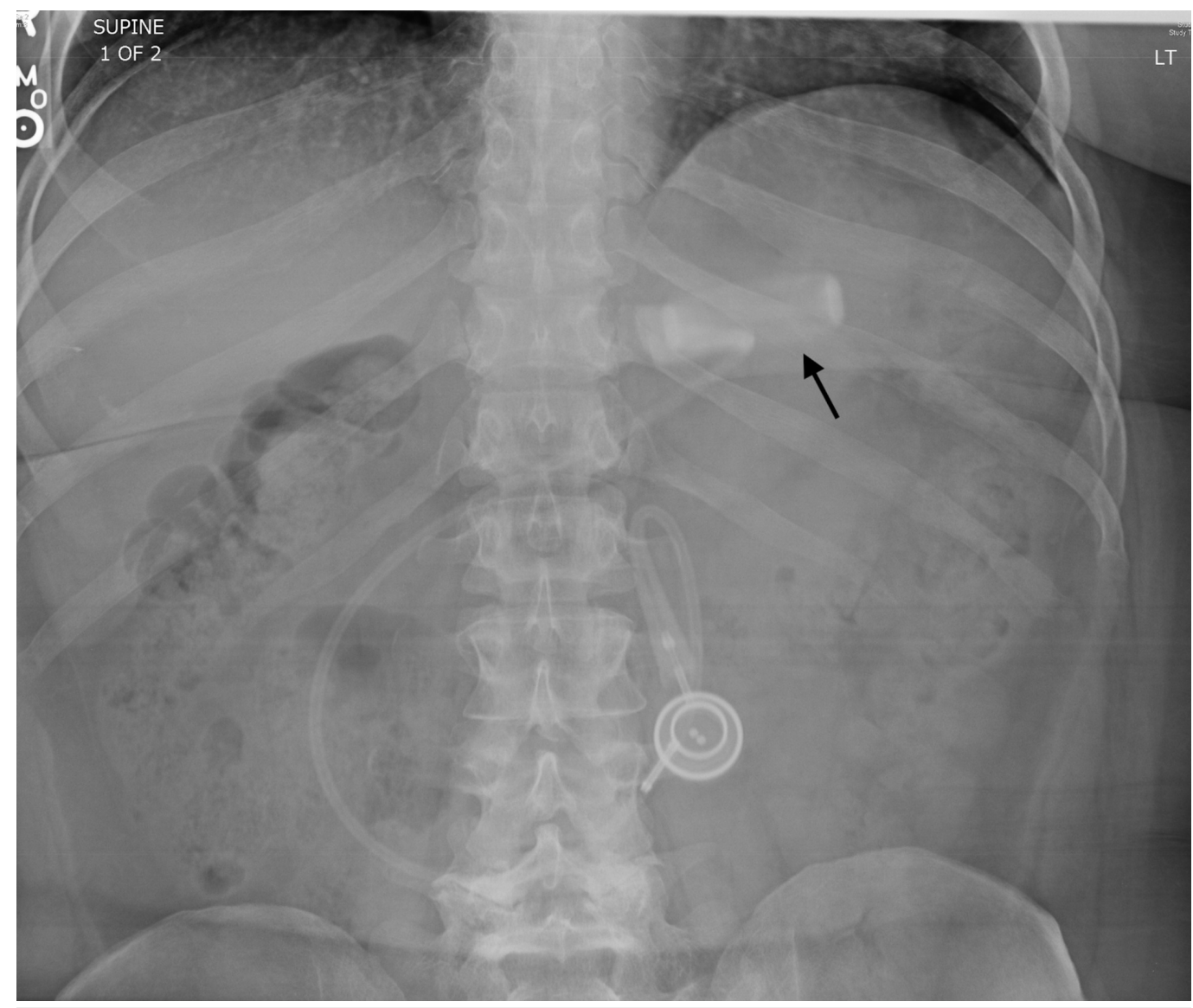

FIGURE 1: Abdominal radiograph demonstrating a horizontal positioning of the lap band (arrow).

\section{Discussion}

The LAGB method has been shown to be a safe and effective weight loss strategy with an average weight loss of $40 \%$ of initial excess body weight [3]. LAGB was once the most popular form of weight loss surgery in the United States due to the simplicity, reversibility, and adjustable nature of the device and procedure [4]. According to the American Society for Metabolic and Bariatric Surgery, in 2011 (the year our patient had her procedure), there were an estimated 158,000 bariatric surgery cases performed, with LAGB accounting for $35.4 \%$, or 56,000 of them [5]. Although the incidence of LAGB cases has decreased drastically over the past eight years, it is necessary to evaluate and document possible presenting symptoms of LAGB complications, as a total of approximately 160,000 patients have had the LAGB procedure since 2011 [5]. 
As seen in this case, the most common major complication of LAGB is band slippage, defined as herniation of distal stomach superiorly through the band resulting in dilation of the proximal pouch and incorrect band placement [6]. LAGB slippage has an approximate lifetime frequency of 5\% [7]. Common presenting symptoms of LAGB slippage include abdominal pain, food intolerance, regurgitation, dysphagia, heartburn, nausea, vomiting, early satiety, and nocturnal vomiting $[8,9]$. The patient described here presented with similar symptoms of nausea and heartburn, but additionally was experiencing globus, nocturnal productive bilious coughing spells, and a chief complaint of chest pain described as cramping and burning that worsened after ingestion of both solids and liquids. Cardiac workup was negative.

Diagnosis of slipped LAGB entails anterior-posterior (AP) abdominal radiographs to view band malposition, and subsequent upper gastrointestinal (GI) series [10, 11]. On AP abdominal radiograph films, a correctly positioned gastric band has a $\phi$ (phi) angle of $4^{\circ}$ to $58^{\circ}$ between the profile of the gastric band and the vertical axis of the spine [6]. As seen in the films from this case, the patient's gastric band is in an abnormal near-horizontal position with a $\phi$ (phi) angle of close to $80^{\circ}$ indicative of band slippage. In addition, correctly positioned bands should be situated approximately $5 \mathrm{~cm}$ below the left hemidiaphragm, have a rectangular appearance, and as seen on upper GI series the proximal pouch should measure no more than $4 \mathrm{~cm}$ at its widest diameter [6]. An "O-sign" for band slippage is classically described when there is an abnormally ovoid shaped appearance of the band seen on abdominal radiographs [12]. An Osign may be described for the presented case, as we can start to see the loss of normal rectangular shape and onset of ovoid appearance of the patient's band.

Recognition of LAGB slippage is important due to possible significant complications if left untreated such as gastric ischemia, necrosis, perforation, and prolapse [9, 10]. Because of this, band slippage should be considered an emergency with urgent band deflation for temporary symptom relief and subsequent definitive treatment with band removal, replacement, or repositioning. Patients presenting with a history of LAGB and signs or symptoms of band slippage should undergo immediate imaging with AP abdominal radiographs and an upper GI series to confirm the diagnosis and expedite treatment to prevent further gastrointestinal complications.

\section{Conclusions}

One of the complications of the LAGB procedure is slippage. This can be readily identified in plain radiographs by the position of the band.

\section{Additional Information \\ Disclosures}

Human subjects: Consent was obtained by all participants in this study. Conflicts of interest: In compliance with the ICMJE uniform disclosure form, all authors declare the following:

Payment/services info: All authors have declared that no financial support was received from any organization for the submitted work. Financial relationships: All authors have declared that they have no financial relationships at present or within the previous three years with any organizations that might have an interest in the submitted work. Other relationships: All authors have declared that there are no other relationships or activities that could appear to have influenced the submitted work.

\section{Acknowledgements}

This research was supported (in whole or in part) by HCA Healthcare and/or an HCA Healthcare affiliated entity. The views expressed in this publication represent those of the author(s) and do not necessarily represent the official views of HCA Healthcare or any of its affiliated entities. 


\section{References}

1. Hales CM, Fryar CD, Ogden CL: Prevalence of Obesity Among Adults and Youth: United States, 2015-2016. NCHS Data Brief. 2017, 288:1-8.

2. Colquitt JL, Pickett K, Loveman E, Frampton GK: Surgery for weight loss in adults . Cochrane Database Syst Rev. 2014, 8:1-242. 10.1002/14651858.CD003641.pub4

3. Himpens J, Cadière G, Bazi M, et al.: Long-term outcomes of laparoscopic adjustable gastric banding. Arch Surg. 2011, 146:802-807. 10.1001/archsurg.2011.45

4. Chung AY, Strassle PD, Schlottmann F, et al.: Trends in Utilization and Relative Complication Rates of Bariatric Procedures. J Gastrointest Surg. 2019, 23:1362-1372. 10.1007/s11605-0183951-2

5. Estimate of Bariatric Surgery Numbers 2011-2017. (2018). Accessed: 2019 June 1: https://asmbs.org/resources/estimate-of-bariatric-surgery-numbers.

6. Sonavane SK, Menias CO, Kantawala KP, et al.: Laparoscopic adjustable gastric banding: what radiologists need to know. Radiographics. 2012, 32:1161-1178. 10.1148/rg.324115177

7. Kodner C, Hartman DR: Complications of adjustable gastric banding surgery for obesity . Am Fam Physician. 2014, 89:813-818.

8. Keidar A, Szold A, Carmon E, et al.: Band slippage after laparoscopic adjustable gastric banding: etiology and treatment. Surg Endosc. 2005, 19:262-267. 10.1007/s00464-003-8261-3

9. Snow JM, Severson PA: Complications of adjustable gastric banding. Surg Clin North Am. 2011, 6:1249-1264. 10.1016/j.suc.2011.08.008

10. Hamdan K, Somers S, Chand M: Management of late postoperative complications of bariatric surgery. Br J Surg. 2011, 98:1345-1355. 10.1002/bjs.7568

11. Seeras K, Prakash S: Laparoscopic Lap Band Placement. StatPearls. StatPearls Publishing LLC, Treasure Island; 2019.

12. Pieroni S, Sommer EA, Hito R, et al.: The "O" sign, a simple and helpful tool in the diagnosis of laparoscopic adjustable gastric band slippage. AJR Am J Roentgenol. 2010, 195:137-141. 10.2214/AJR.09.3933 